\title{
Prolonged Immunodeficiency in a Patient with Burkitt's Lymphoma after Treatment with Rituximab and Chemotherapy
}

\section{Arjun Adapa ${ }^{1}$ and Sudhir Sekhsaria ${ }^{2 *}$}

${ }^{1}$ University of Maryland, College Park, MD, USA

${ }^{2}$ MedStar Union Memorial Hospital, Baltimore, MD, USA

"Corresponding author: Sudhir Sekhsaria, MD, MedStar Union Memorial Hospital, 3333 N. Calvert Street Suite 520, Baltimore, MD 21218, USA, Tel: 4105546516; Fax: 4105546517; E-mail: asthma4@yahoo.com

Received date: January 27, 2015; Accepted date: March 03, 2015; Published date: March 10, 2015

Copyright: (C) 2015 Adapa A, et al. This is an open-access article distributed under the terms of the Creative Commons Attribution License, which permits unrestricted use, distribution, and reproduction in any medium, provided the original author and source are credited.

\begin{abstract}
Common-variable immunodeficiency (CVID) is a heterogeneous disorder characterized by recurrent bacterial infections, hypogammaglobulinemia, and impaired antibody responses. Patients with CVID can remain undiagnosed for many years but carry an increased risk for developing B cell derived non-Hodgkin's lymphomas, such as Burkitt's lymphoma. Screening for CVID in patients diagnosed with Burkitt's lymphoma is necessary before prescribing treatments, because certain regimens may significantly increase the risk for flare-up of CVID that could result in prolonged immunodeficiency. We present a patient who was diagnosed with Burkitt's lymphoma and sustained prolonged severe immunodeficiency after receiving a complete course of rituximab and chemotherapy treatment. This case report illustrates the need for an immunological work-up in lymphoma patients before initiation of treatment because of the increased incidence of lymphoma in patients with immunodeficiencies. Patients with lymphoma should also be monitored longitudinally for immunodeficiencies after treatment with rituximab with or without chemotherapy.
\end{abstract}

Keywords: CVID; Burkitt's lymphoma; Rituximab; Chemotherapy

\section{Introduction}

Burkitt's lymphoma, a non-Hodgkin's B cell lymphoma, is caused by translocation and subsequent deregulation of the c-myc oncogene on chromosome 8 [1]. Rituximab, a common treatment for Burkitt's lymphoma, is an anti-CD20 chimeric antibody depreciating CD20expressing $\mathrm{B}$ cells in lymphoid tissues and circulation. Adjuvant monoclonal antibody therapy with rituximab has successfully achieved improved outcomes for patients. Treatment with rituximab results in $90 \%$ reduction of $\mathrm{CD} 20+\mathrm{B}$ cells. Its application is intended to eliminate malignant $\mathrm{B}$ cell clones [2]. The degree and duration of $\mathrm{B}$ cell depletion and its effects on immunoglobulin (Ig) levels in Burkitt's lymphoma patients is not fully understood. There is even evidence that rituximab interventions may modulate the $\mathrm{T}$ cell compartment as well [3].

There is an increased risk of developing non-Hodgkin's B cell lymphomas in patients with CVID. Patients with CVID often acquire inflammatory and autoimmune disorders, malignancies and systemic granuloma formations. Most of the malignancies affect the $\mathrm{B}$ cell compartment, with the development of non-Hodgkin's B cell lymphomas posing a major risk [4]. Other patients develop symptoms of non-classic CVID such as defects in $\mathrm{T}$ cell development and secondary B cell deficiency [5]. Autoimmune manifestations are found in the form of cytopenias (usually acting as the initial presentation of CVID), such as immune thrombocytopenic purpura (ITP) and autoimmune hemolytic anemia (AIHA). A small proportion of CVID patients have defects in $\mathrm{CD} 20 \mathrm{~B}$ cell surface protein. It has been suggested that $\mathrm{CD} 20$ dissociation from the BCR signalosome during early B cell activation might predispose individuals to CVID [6].
Acquired hypogammaglobulinemia is frequently concomitant with B cell derived non-Hodgkin's lymphomas. Treatment of lymphomas with cytoreductive chemotherapy or drugs that can cause amplified protein loss can lead to acquired hypogammaglobulinemia [7]. Immunosuppressive drugs targeting B lymphocytes can additionally result in similar clinical effects. It is not well known whether rituximab, chemotherapy, or combined treatment leads to prolonged immunodeficiency. We present a patient with Burkitt's lymphoma who developed severe and prolonged immunodeficiency after undergoing rituximab and chemotherapy treatment.

\section{Case Presentation}

A 43-year-old woman reported swelling in her right inguinal lymph node approximately five years ago, prompting a lymph node biopsy. A CT scan revealed a $5 \mathrm{~cm}$ soft tissue mass, and final pathology confirmed a diagnosis of Burkitt's lymphoma nine days later. Prior to the start of her treatment regimen, her medical history was not significant for any instances of pneumonia or sinus infections and she had normal levels of white blood cells $(5.8 \times 10 \mathrm{E} 3 / \mu \mathrm{L})$, platelets $(219 \times 10 \mathrm{E} 3 / \mu \mathrm{L})$, absolute neutrophils $(4.1 \times 10 \mathrm{E} 3 / \mu \mathrm{L})$ and lymphocytes $(1.2 \times 10 \mathrm{E} 3 / \mu \mathrm{L})$ (Table 1$)$. A comprehensive immunology laboratory assessment including immunoglobulins, however, was not administered before and after her diagnosis of Burkitt's lymphoma.

After her diagnosis of lymphoma, the patient underwent a combination of chemotherapy and rituximab treatment for two-anda-half months. Briefly, each treatment cycle consisted of CVP (cyclophosphamide-vincristine-prednisone) chemotherapy with highdose cyclophosphamide $\left(1500 \mathrm{mg} / \mathrm{m}^{2}\right)$ and vincristine $\left(1.4 \mathrm{mg} / \mathrm{m}^{2}\right)$ on day, prednisone $(100 \mathrm{mg})$ on days 1 through rituximab $\left(375 \mathrm{mg} / \mathrm{m}^{2}\right)$ on days 1 and 8 and high-dose methotrexate $\left(3 \mathrm{~g} / \mathrm{m}^{2}\right)$ and leucovorin $(25 \mathrm{mg})$ rescue on day 8 . Additionally, filgrastim (G-CSF) $(480 \mu \mathrm{g})$ was 
given subcutaneously (SC) once daily beginning on day 3 and cytarabine intrathecally (IT) on days, 4 and 11 . After two cycles, the patient continued with consolidation therapy consisting of rituximab and high-dose cyclophosphamide for 4 days, followed by rituximab once weekly and G-CSF SC daily until the end of treatment.

Approximately four months after her final treatment with rituximab, the patient began developing upper respiratory tract infections, discolored rhinorrhea and nasal congestion with a pattern characterized by brief, positive response to oral antibiotic followed by rapid relapse within two weeks. Over the next eight months, the patient had recurrent sinus infections every 2-4 weeks, requiring treatment with antibiotic courses. A CT scan done at that time revealed mucosal thickening in bilateral maxillary sinuses and thickening in her ethmoid cavity. She was then referred to our allergy and immunology clinic for an allergy and immunology work-up.

An allergy skin-prick test was positive for tree, grass, ragweed pollens and dust mites. Her initial immune work-up revealed low IgG ( $<60 \mathrm{mg} / \mathrm{dL}), \operatorname{IgA}(<5 \mathrm{mg} / \mathrm{dL})$, and $\operatorname{IgM}(<4 \mathrm{mg} / \mathrm{dL})$. She demonstrated no response to all 14 serotypes of pneumococcal bacteria 4 weeks after vaccination with pneumovax. She was started on monthly intravenous immunoglobulin (IVIg) therapy $(500 \mathrm{mg} / \mathrm{kg}$ ). Her subsequent trough levels of IgG were normal, but as expected, IgA and IgM continued to be deficient (Table 1), because IVIg does not replace IgA and IgM. The patient continued with a significant deficiency in her white blood cell numbers $(3.0 \times 10 \mathrm{E} 3 / \mu \mathrm{L})$, neutrophils $(2.0 \times 10 \mathrm{E} 3 / \mu \mathrm{L})$, lymphocytes $(0.70 \times 10 \mathrm{E} 3 / \mu \mathrm{L})$ (Figure 1$)$, platelets $(112 \times 10 \mathrm{E} 3 / \mu \mathrm{L})$, and CD4 $(266 /$ $\mu \mathrm{L})$ for a prolonged period of up to 42 months after finishing chemotherapy and rituximab treatment. The patient had a good response to the IVIg with an average of 1.5 sinus infections every year and no other major opportunistic infections. The results are summarized in Table 1.

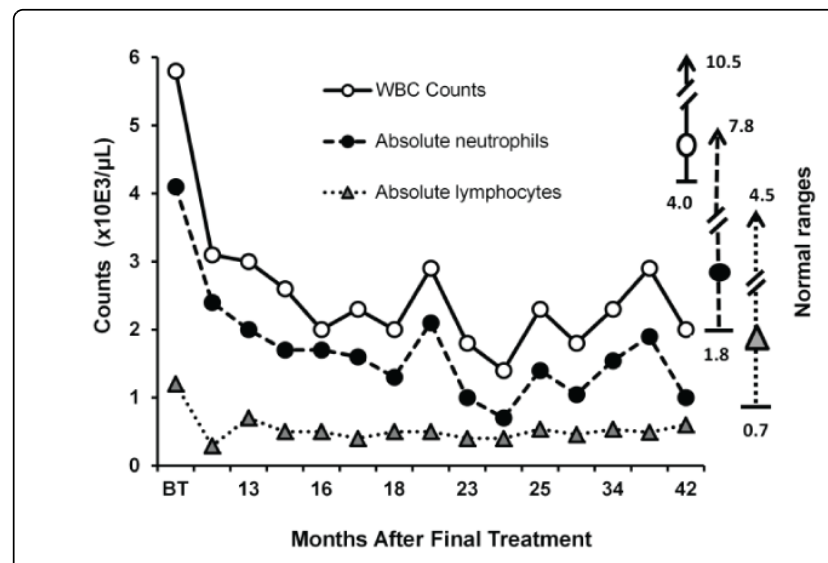

Figure 1: White blood cell, neutrophil, and lymphocyte counts in the patient before and after chemotherapy and rituximab.

Normal ranges are as follows: WBC - 4.0-10.5 $\times 10 \mathrm{E} 3 / \mu \mathrm{L}$, Neutrophils - 1.8-7.8×10E3/ $\mu \mathrm{L}$, Lymphocytes - 0.7-4.5×10E3/ $\mu \mathrm{L}$. BT refers to before treatment. $\mathrm{X}$-axis numbers correspond to months after cessation of treatment.

\begin{tabular}{|c|c|c|c|c|c|c|c|c|}
\hline & $\lg \mathbf{G}^{1}$ & $\lg A^{2}$ & $\lg ^{3}$ & WBC $^{4}$ & Platelet $^{5}$ & Neutrophils (abs) ${ }^{6}$ & Lymphocytes (abs) $^{7}$ & CD4 ${ }^{8}$ \\
\hline $\begin{array}{l}\text { Before Initiation of } \\
\text { Treatment }\end{array}$ & - & - & - & 5.8 & 219 & 4.1 & 1.2 & - \\
\hline $1 \mathrm{mo}$ & - & - & - & 3.1 & 69 & 2.4 & 0.29 & - \\
\hline $13 \mathrm{mo}$ & $<60$ & $<5$ & $<4$ & 3.0 & 112 & 2.0 & 0.70 & 266 \\
\hline $16 \mathrm{mo}$ & 27 & $<5$ & $<4$ & 2.0 & 103 & 1.7 & 0.5 & 206 \\
\hline $23 \mathrm{mo}$ & $1097^{*}$ & 11 & 4 & 1.8 & 119 & 1.0 & 0.40 & - \\
\hline $27 \mathrm{mo}$ & 1279 & $<20$ & $<1$ & 2.3 & 122 & 1.4 & 0.54 & 181 \\
\hline $34 \mathrm{mo}$ & 1089 & $<4$ & $<1$ & 2.3 & 135 & 1.5 & 0.54 & - \\
\hline $42 \mathrm{mo}$ & 1128 & $<5$ & $<4$ & 2.0 & 129 & 1.0 & 0.60 & - \\
\hline
\end{tabular}

Table 1: Immunological laboratory values of the patient with Burkitt's lymphoma before diagnosis and after cessation of treatment with chemotherapy and rituximab. Normal ranges are given as follows: $1(700-1600 \mathrm{mg} / \mathrm{dL}) ; 2(90-415 \mathrm{mg} / \mathrm{dL}) ; 3(40-230 \mathrm{mg} / \mathrm{dL}) ; 4(4.0-10.5 \times 10 \mathrm{E} 3 /$ $\mu \mathrm{L}) ; 5(150-415 \times 10 \mathrm{E} 3 / \mu \mathrm{L}) ; 6(1.8-7.8 \times 10 \mathrm{E} 3 / \mu \mathrm{L}) ; 7(0.7-4.5 \times 10 \mathrm{E} 3 / \mu \mathrm{L}) ; 8(359-1520 / \mu \mathrm{L})$. Month in leftmost column refers to elapsed time after ending treatment.

\section{Discussion}

Patients who have CVID are more prone to developing nonHodgkin's B cell lymphomas like Burkitt's lymphoma, and incidences of lymphoma are more common in females than males [8]. Patients with CVID can go undiagnosed and remain asymptomatic for a number of years [9]. In the case presented, however, the patient likely developed the prolonged immunodeficiency secondary to treatment with Rituximab and / or chemotherapy and not due to preexisting
CVID. The patient had no significant history of recurrent sinusitis, bronchitis or pneumonia prior to starting treatment with Rituximab and chemotherapy. This highlights the need for an immunological assessment in patients with lymphoma prior to their treatment with chemotherapy and/or rituximab to rule out preexisting CVID.

Rituximab typically does not lead to prolonged deficiencies in immunoglobulin levels because of the presence of long-lived plasma cells [10]. However, a study demonstrated prolonged 
Citation: Adapa A, Sekhsaria S (2015) Prolonged Immunodeficiency in a Patient with Burkitt's Lymphoma after Treatment with Rituximab and Chemotherapy. J Mol Genet Med 9: 165. doi:10.4172/1747-0862.1000165

Page 3 of 3

hypogammaglobulinemia after rituximab treatment in a subset of patients for up to 42 months [11]. In one case study, rituximab was found to aggravate underlying CVID in a 34-year-old male patient [12]. Routine baseline B-cell numbers and serum immunoglobulin levels before starting immunomodulatory therapy are required to help distinguish primary immunodeficiency diseases from secondary rituximab-induced, transient, and, at times, prolonged immune suppression [13]. It is unknown whether the addition of chemotherapy to rituximab can enhance the risk of developing prolonged hypogammaglobulinemia. Hence, patients treated with rituximab and/or chemotherapy should have serial laboratory assessments for earlier diagnosis of immunodeficiency. It possible that a subset of patients with a genetic predisposition may develop prolonged immunodeficiency after treatment with rituximab and/or chemotherapy.

This case report illustrates the need for an immunological work-up before initiation of treatment in all patients with lymphoma, because patients with CVID and other immunodeficiencies are at an increased risk for developing such malignancies. Our case report also demonstrates the need for serial immunological assessments in patients receiving rituximab with or without chemotherapy, because such treatments may lead to prolonged immunodeficiency in a subset of patients. Furthermore, our case report highlights the need for a larger, prospective study of patients receiving rituximab and/or chemotherapy for lymphomas or other autoimmune disorders to enhance our understanding on the risks of developing prolonged immunodeficiency due to such treatments.

\section{References}

1. Erikson J, ar-Rushdi A, Drwinga HL, Nowell PC, Croce CM (1983) Transcriptional activation of the translocated c-myc oncogene in burkitt lymphoma. Proc Natl Acad Sci U S A 80: 820-824.

2. Weiner GJ (2010) Rituximab: mechanism of action. Semin Hematol 47: $115-123$.
3. Stasi R, Del Poeta G, Stipa E, Evangelista ML, Trawinska MM, et al. (2007) Response to B-cell depleting therapy with rituximab reverts the abnormalities of T-cell subsets in patients with idiopathic thrombocytopenic purpura. Blood 110: 2924-2930.

4. Ahn S, Cunningham-Rundles C (2009) Role of B cells in common variable immune deficiency. Expert Rev Clin Immunol 5: 557-564.

5. Driessen GJ, Dalm VA, van Hagen PM, Grashoff HA, Hartwig NG, et al. (2013) Common variable immunodeficiency and idiopathic primary hypogammaglobulinemia: two different conditions within the same disease spectrum. Haematologica 98: 1617-1623.

6. van de Ven AA, Compeer EB, Bloem AC, van de Corput L, van Gijn M, et al. (2012) Defective calcium signaling and disrupted CD20-B-cell receptor dissociation in patients with common variable immunodeficiency disorders. J Allergy Clin Immunol 129: 755-761.

7. Jaffe EF, Lejtenyi MC, Noya F, Mazer BD (2001) Secondary hypogammaglobulinemia. Immunology And Allergy Clinics of North America 21: 141-163.

8. Cunningham-Rundles C (2012) The many faces of common variable immunodeficiency. Hematology Am Soc Hematol Educ Program 2012: 301-305.

9. Abolhassani H, Sagvand BT, Shokuhfar T, Mirminachi B, Rezaei N, et al. (2013) A review on guidelines for management and treatment of common variable immunodeficiency. Expert Rev Clin Immunol 9: 561-574.

10. Gea-Banacloche JC (2010) Rituximab-associated infections. Semin Hematol 47: 187-198.

11. Roberts DM, Jones RB, Smith RM, Alberici F, Kumaratne DS, et al. (2014) Rituximab-associated hypogammaglobulinemia: Incidence, predictors and outcomes in patients with multi-system autoimmune disease. J Autoimmun In press.

12. Mogensen TH, Magnus Bernth-Jensen J, Petersen CC, Petersen MS, Nyvold C, et al. (2013) Common variable immunodeficiency unmasked by treatment of immune thrombocytopenic purpura with Rituximab. BMC Hematology 13:4.

13. Kaplan B, Kopyltsova Y, Khokhar A, Lam F, Bonagura V (2014) Rituximab and immune deficiency: case series and review of the literature. J Allergy Clin Immunol Pract 2: 594-600. 